\title{
Valorización del patrimonio industrial agroalimentario: Los silos del «Proyecto Titanes» (Ciudad Real, España) ${ }^{1}$
}

\author{
The Revitalization of Agri-Food's Industrial Heritage: The Silos of the \\ "Titans Project" in Ciudad Real, Spain
}

\author{
María del Carmen Cañizares Ruiz \\ Universidad de Castilla-La Mancha \\ Departamento de Geografía y Ordenación del Territorio \\ http:/ / orcid.org/0000-0002-2153-8497 \\ MCarmen.Canizares@uclm.es
}

Recibido: 22/06/2020; Revisado: 15/10/2020; Aceptado: 22/10/2020

\section{Resumen}

Los silos verticales de cereales constituyen edificaciones claramente representativas del patrimonio industrial agroalimentario, dados sus valores históricos, técnicos, científicos, etc. En España, la Red de Silos y Graneros agrupó 667 dentro de la política intervencionista del franquismo que estuvieron activos hasta la entrada de España en la Unión Europea. Hoy una gran mayoría se encuentran abandonados y algunos se han rehabilitado para otros usos (culturales, administrativos, ...). Presentamos los que se han incluido en el Proyecto Titanes, una original propuesta de valorización a través de intervenciones de arte urbano en nueve municipios de la provincia de Ciudad Real.

Palabras clave: patrimonio industrial agroalimentario, silos, Proyecto Titanes, arte urbano, Ciudad Real.

\begin{abstract}
The vertical grain silos are buildings clearly representative of the agri-food industrial heritage given their historical, technical, scientific values, etc. In Spain, the Red de Silos y Graneros grouped 667 within the interventionist policy of the Franco dictatorship that were active until Spain's entry into the European Union. Today, a large majority are abandoned and some have been rehabilitated for other

1 Este artículo se enmarca en el Proyecto Los paisajes culturales agrarios en Castilla-La Mancha como base del desarrollo territorial (SBPLY/19/180501/000041), Junta de Comunidades de Castilla-La Mancha y Fondos FEDER (UE).
\end{abstract}


Valorización del patrimonio industrial agroalimentario: Los silos del «Proyecto Titanes»

uses (cultural, administrative,...). We present those that have been included in the Titanes Project, an original proposal for valuing silos through street art in nine towns in the province of Ciudad Real.

Key words: agri-food industrial heritage, silos, Titanes Project, street art, Ciudad Real.

\section{INTRODUCCIÓN}

Los silos, y también los graneros, son depósitos para el almacenaje del trigo y otros cereales, construidos de ladrillo u hormigón, preferentemente, y se integran dentro de lo que se denomina patrimonio industrial. Esta tipología de patrimonio se compone de los restos de la cultura industrial materializada en «edificios y maquinaria, talleres, molinos y fábricas, minas y sitios para procesar y refinar, almacenes y depósitos, lugares donde se genera, se transmite y se usa energía, medios de transporte y toda su infraestructura, así como los sitios donde se desarrollan las actividades sociales relacionadas con la industria», siguiendo la Carta de Nizhny Tagil sobre Patrimonio Industrial (2003), promovida por TICCIH (The International Committee for the Conservation of the Industrial Heritage) e ICOMOS (International Council on Monuments and Sites), para el período que se extiende desde la Revolución Industrial hasta la actualidad (ICOMOS, 2003: 2). Elementos que poseen un valor social como parte del registro de vidas de hombres y mujeres corrientes, y como tales, proporcionan un importante sentimiento de identidad; un valor tecnológico y científico en la historia de la producción, la ingeniería, la construcción; pueden tener un valor estético por la calidad de su arquitectura, diseño o planificación; y muchos de ellos tienen un valor universal reconocido por la UNESCO al incluirlos en la Lista del Patrimonio Mundial. Además, estos valores no son exclusivos del propio elemento de patrimonio industrial, sino que son intrínsecos del lugar en el que se ubican, de su entramado, de sus componentes, de su maquinaria y de su funcionamiento, se vinculan con el paisaje industrial, la documentación escrita, y también con los recuerdos y las costumbres de las personas. Especialmente relevante es que, en general, cada vez se encuentran más y mejor valorados por sus implicaciones en los procesos de desarrollo endógeno, enfatizando el componente territorial, es decir, el contexto/ entorno y el paisaje del que forman parte (CAÑIZARES et al., 2019: 184).

No obstante, la valoración de los elementos materiales einmateriales derivados de la industrialización desde el ámbito patrimonial ha sido tardía en España y se relaciona con la ampliación conceptual del término patrimonio junto con el protagonismo del territorio (nueva cultura del territorio). De hecho, el patrimonio industrial ha sido «el gran olvidado del siglo XX» (SÁnCHEZ Mustieles, 2011) y no es hasta finales del siglo pasado cuando, junto con los trabajos científicos desde distintas disciplinas (geografía, historia, arquitectura, ingenierías,...), comienzan a aparecer iniciativas sociales e institucionales para promover su puesta en valor, a las que se unen instrumentos normativos que buscan proteger, conservar $y$, en el mejor de los casos, avanzar hacia la reutilización de algunos elementos. En 
el ámbito de la planificación destaca, a escala estatal, la aprobación en 2001 del Plan Nacional de Patrimonio Industrial por el Instituto del Patrimonio Cultural de España (con actualizaciones en 2011 y 2016), centrado en la identificación de los elementos de patrimonio industrial y sus huellas sobre el territorio como nuevos bienes culturales y recursos activos para fomentar programas de desarrollo sostenible a escala local y regional; un documento que proporciona un enfoque sólido y avanzado en favor de la correcta gestión de estos nuevos bienes que deben ser representados e interpretados a través de una lectura actualizada, integrada y científica ${ }^{2}$.

A partir de la conceptualización teórica de unos elementos concretos, los silos de gran entidad, tipificados dentro de un patrimonio industrial específico, el agroalimentario, y de la revisión de su evolución en España durante el período franquista, el objetivo es presentar un proyecto concreto de intervención a través del arte urbano (street art): el Proyecto Titanes. Enél se incluyen diez silos, localizados en nueve municipios de la provincia de Ciudad Real (Castilla-La Mancha, España), que se han sido objeto de atención institucional, contribuyendo, así, a su puesta en valor desde el punto de vista cultural. Un análisis que se contextualiza en la atención concedida a las «ruinas industriales» desde finales del siglo pasado, dadas las enormes potencialidades que tienen por las posibilidades de albergar nuevos usos, además de ser la base de iniciativas (centros culturales, ecomuseos, parques, etc.). Ello ha servido, en muchos casos, para conservar edificaciones que, despojadas de su función originaria, se «reinventan» para la sociedad actual en relación con las actividades terciarias y contribuyen a preservar la memoria del trabajo.

Los silos, representativos del grupo de «almacenes y depósitos», abandonados en muchos casos y rehabilitados en algunos, poseen diversos valores, como expondremos en una breve revisión sobre los integrados en la Red Nacional de Silos y Graneros. Son pocos los ejemplos de aquellos que son intervenidos a partir del arte, como sucede con los que componen el Proyecto Titanes, buscando sacarlos del olvido a través del arte urbano aprovechando que los espacios industriales abandonados constituyen, en ocasiones, auténticas «escenografías que pueden ser potenciadas en los nuevos usos, además de servir de inspiración para el arte contemporáneo en disciplinas tan diversas como el cine, la fotografía, el teatro o la ópera» (BLANCO y Río, 2015: 229). La metodología se centrará, en función de las fuentes disponibles, en la revisión de la amplia bibliografía disponible, la documentación sobre el proyecto analizado y el imprescindible trabajo de campo. Los resultados esperados se concretan en la revisión teórica de lo sucedido en torno a los silos en España y la caracterización de aquellos que se intentan valorizar a partir de las intervenciones artísticas vinculadas con el Proyecto Titanes, aún no finalizado.

2 IPCE. Instituto del Patrimonio Cultural de España (2016): Plan Nacional de Patrimonio Industrial, Ministerio de Cultura y Deportes, Madrid. https://sede.educacion.gob.es/publiventa/descarga. action?f_codigo_agc $=15114$ C [Consulta: 15/10/2020]. 


\section{BASES METODOLÓGICAS}

Las bases metodológicas para abordar el objeto de estudio, como se ha indicado, parten de la bibliográfica disponible, muy prolija, que ha permitido abordar la caracterización teórica del patrimonio industrial agroalimentario, de manera general, para desarrollar aspectos concretos referidos a los silos y graneros en España. También se ha utilizado documentación específica que ha favorecido la presentación del Proyecto Titanes, representativo de las actuaciones de puesta en valor cultural por medio del arte en esta tipología de elementos de patrimonio industrial agroalimentario y ejemplo de inclusión social. Finalmente, el trabajo de campo ha conformado el complemento indispensable para el conocimiento directo de las intervenciones realizadas.

La bibliografía disponible sobre el concepto de patrimonio industrial agroalimentario y, de forma concreta, sobre los silos, es extensa. Destacamos algunas obras conjuntas como Patrimonio Industrial Agroalimentario. Testimonios cotidianos del diálogo intercultural (Álvarez, 2009); algunos trabajos académicos como Los gigantes del siglo XX. Reinterpretación en el siglo XXI (SALAMANCA, 2008) y, sobre todo, la Tesis Doctoral Catedrales olvidadas. La Red Nacional de Silos en España (19491990) (AzCÁrATE, 2009), en la que se realiza un exhaustivo análisis de la evolución de la red nacional de silos, de las construcciones y de sus tipologías, entre otros. A ellos se unen numerosas publicaciones, principalmente artículos científicos relacionados con esta temática. Entre ellos, el estudio «History, construction characteristics and possible reuse of Spain'snetwork of silos and granaries», publicado en la revista Land Use Policy (Fernández et al., 2017: 298), en el que se realiza un amplio análisis de los silos integrados en la Red Nacional durante el franquismo en base a sus características constructivas, tipologías y posibilidades de reutilización, con especial atención a los localizados en la región de Castilla y León (España).

Especialmente relevantes son algunos documentos como la Carta de Nizhny Tagil sobre Patrimonio Industrial (2003), en la que se aboga por la catalogación, el registro y la investigación, así como por la necesidad de protección legal para todos sus elementos, considerados parte del patrimonio cultural de un territorio, junto con el mantenimiento y la conservación (ICOMOS, 2003). En España, la Carta de Sevilla de Patrimonio Industrial (2018) promovida por un conjunto de expertos (SoBRINO y SANZ, 2018) aborda los retos para el siglo XXI en esta temática planteando un enfoque renovado que facilite la acción transdiciplinar dada su complejidad y transversalidad. Por su parte, la Carta de Baeza sobre el Patrimonio Agrario (2012) reconoce la importancia del «conjunto de bienes naturales y culturales, materiales e inmateriales, generados o aprovechados por la actividad agraria a lo largo de la historia» (CASTILLO, 2013: 32), incluyendo la valoración de edificaciones (bienes inmuebles), como en este caso. Sin duda, un patrimonio de gran relevancia al que no siempre se le ha concedido la atención merecida.

Para profundizar en el ámbito temático de los silos sobresale el Grupo de 
Investigación Silos y Graneros ${ }^{3}$ que, desde 2004, promueve la puesta en valor de la histórica Red Nacional mediante acciones para su documentación, valorización, conservación y difusión, considerando los contextos urbanos y rurales donde se insertan para promover proyectos de revitalización bajo nuevos usos adaptados a las demandas sociales actuales. Entre sus objetivos, también están: denunciar su abandono, destrucción o saqueo incontrolado de los bienes, edificaciones y maquinaria en ellos alojados, así como servir de plataforma de difusión científica. $\mathrm{Su}$ inventario de libre consulta ofrece información actualizada y contrastada de las unidades que conformaron la Red. Significativa también es la iniciativa del colectivo cultural Proyecto Silos, ${ }^{4}$ iniciado en 2013 por arquitectos y estudiantes para promover el debate sobre posibles nuevos usos. Su objetivo es también difundir, poner en valor, rehabilitar e investigar el patrimonio industrial agrario desatendido en el marco de un «espacio global de intercambio sobre silos que revierta positivamente en las comunidades rurales» (BOCANEGRA, 2016: 18).

En lo relativo a la profundización en el proyecto de intervención artística y de valorización cultural de los silos presentados en la provincia de Ciudad Real, destacamos, el propio Proyecto Titanes en formato inédito, facilitado por la Diputación Provincial de Ciudad Real (2020). También, dada la información preferentemente visual que ofrece, es de reseñar el portal web del mismo proyecto. ${ }^{5}$

\section{PATRIMONIOINDUSTRIAL AGROALIMENTARIO, SILOS Y GRANEROS EN ESPAÑA}

El análisis de los silos en España y, de forma concreta en la provincia de Ciudad Real que abordaremos en la segunda parte del texto, requiere que prestemos atención, inicialmente, al marco teórico derivado del concepto de patrimonio industrial agroalimentario, al que se vinculan, para profundizar, posteriormente, en la Red Nacional de Silos y Graneros.

\subsection{Los silos en el contexto del patrimonio industrial agroalimentario}

El patrimonio industrial agroalimentario, también denominado patrimonio agroindustrial o patrimonio industrial agrario, integra elementos (materiales e inmateriales) que son resultado de la acción del hombre en el medio para cultivar alimentos (cereales, vino, aceite, caña de azúcar, café, cacao, tabaco, etc) y su transformación a través de procesos industriales. Elementos que conforman una tipología patrimonial a la que se le ha prestado muy poca atención institucional, «que aún está poco considerada a pesar del importante papel que desempeñó en el desarrollo socio-cultural de nuestra historia reciente» (BOCANEGRA, 2016: 18) y en la que existen ciertos «déficits en el campo de la investigación y de la historia industrial» (Álvarez, 2009: 9).

3 https://silosygraneros.es [Consulta: 15/10/2020].

4 http://www.proyectosilos.com [Última consulta: 15/10/2020].

5 https://iamtitanes.com [Última consulta: 15/10/2020]. 
Unos de estos elementos materiales son los silos, construcciones que conforman bienes inmuebles singulares para el almacenaje y depósito de los productos agrarios, cereales principalmente, que son sometidos a una adecuada conservación y transformación mediante procesos mecánicos (maquinaria) para obtener el producto final, refinado y listo para el consumo (cebada, trigo, centeno, avena, maíz ...). Su origen, vinculado al aprovechamiento cerealístico, los convierten en piezas clave de los «paisajes de granos del siglo XX» (LANDI, 2019: 47), dada su relación con las áreas rurales. Se insertan en un contexto territorial específico como componentes singulares y, en ocasiones, se convierten en recursos del territorio cuando se han conservado y reutilizado al servicio de las economías terciarias. Su grandiosidad, aun perdida su función, provoca que se les haya denominado "gigantes del siglo XXI» (SALAMANCA, 2008), "catedrales olvidadas» (AzCÁRATE, 2009) o «rascacielos rurales» (VIDIGAL, 2019), entre otras. Los más antiguos se comenzaron a construir en Estados Unidos, concretamente en Búffalo donde, en 1842, Joseph Dart ideó el primer «elevador de grano» (grain elevator) para el almacenamiento del cereal (silo), a los que siguieron otros en Canadá y Argentina. Estas primeras construcciones fascinaron a arquitectos como W. Gropius y Le Corbusier (SALAMANCA et al., 2012) y «fueron un claro precedente del movimiento moderno europeo» en arquitectura (SOBRINO, 1996: 205). En Europa, los primeros se edificarían en Alemania e Italia en torno a 1900, de la mano fundamentalmente de los ingenieros (AzCÁRATE, 2009: 41).

Sus valores, como ya hemos señalado, están fuera de toda duda. En España, siguiendo el Plan Nacional de Patrimonio Industrial ${ }^{6}$, al que antes hemos aludido, como elementos que forman parte del patrimonio industrial en el sentido amplio, se han convertido en nuevos bienes culturales y en recursos activos para fomentar programas de desarrollo sostenible a escala local y regional. El Plan incluye los silos que integran conjuntos industriales como las Fábricas de Cervezas de El Águila en Madrid (hoy reconvertida en Biblioteca Joaquín Leguina y Archivo Regional de la Comunidad de Madrid) y La Zaragozana en Zaragoza, con sus silos metálicos pintados, uno de los pocos ejemplos de intervención artística existentes en España. También se incluyen los silos de las Fábricas de Harinas Polo, la Ceres aragonesa en Villanueva de Gállego (Zaragoza), la Harinera los Monegros en Saruñena (Huesca) y de la Harinera de Plasencia (Cáceres), junto con los silos de las Fábricas de Cementos Portland localizadas en Morata de Jalón (Zaragoza), de hormigón, y en Olazagutia (Navarra), metálicos. La mayor parte de estos conjuntos también se han incluido en la exposición itinerante 100 Elementos de Patrimonio Industrial en España, promovida por TICCIH-España.

No obstante, los silos creados fundamentalmente para el almacenamiento de cereal en la España rural interior, principalmente, han gozado de muy poca atención institucional y, mayoritariamente, han languidecido una vez perdida su función agravando su estado de degradación, hecho que contrasta con la importancia de su presencia en algunos municipios, al menos desde el ámbito visual y paisajístico como verdaderos hitos, más aún cuando los relacionamos

6 Ver nota $\mathrm{n}^{\circ} 2$. 
con la memoria del trabajo para la población local. En palabras de AzCÁRATE (2009: $487)$, «existen pocas experiencias arquitectónicas y paisajísticas tan emocionantes como las que se pueden percibir recorriendo las llanuras castellanas con el objetivo de observar y disfrutar la presencia de los silos, esas catedrales olvidadas que imperturbables marcan y referencian el territorio con altiva dignidad». Desde el análisis geográfico cada vez se concede mayor atención a los elementos del patrimonio industrial y a su reutilización bajo diferentes fórmulas, especialmente cuando pueden contribuir a la resiliencia de áreas desfavorecidas mediante nuevos usos, rehabilitaciones y/o intervenciones que permitan incorporarlos a las estrategias de desarrollo territorial. Así ha sucedido con algunos rehabilitados para usos administrativos y culturales en pequeños municipios españoles como La Albuera (Badajóz) para albergar dependencias del ayuntamiento o Pozoblanco (Córdoba) como teatro municipal.

\subsection{La Red Nacional de Silos y Graneros}

La Red Nacional de Silos y Graneros se crea en España después de la Guerra Civil durante la dictadura franquista promoviendo la construcción de un conjunto de almacenes de cereal en continuo crecimiento, silos (verticales) y graneros (horizontales), de los cuales nos interesan los primeros. Responde a una estrategia de regeneración de la agricultura nacional, sin materiales ni técnicas vanguardistas, resultado de un enorme esfuerzo realizado por unos ingenieros ${ }^{7}$ ajenos al debate arquitectónico nacional e internacional con «el único objetivo de establecer una red (...) que fuera capaz de garantizar una regulación efectiva del comercio del cereal» (AzCÁRATE, 2002: 55), siguiendo los principios de «utilidad, sencillez y economía», puntualmente apoyados por arquitectos. Algunos precedentes de estas construcciones los encontramos en el silo de hormigón armado construido en el barrio de Zorroza de Bilbao en 1924, proyectado por el arquitecto Federico de Ugalde, el de la empresa Agromán en Salamanca y los silos cilíndricos de hormigón armado de la Panificadora de Vigo, edificados en 1930 por el arquitecto Manuel Gómez Román y el ingeniero Otto Warner, salvados del derribo gracias a la acción ciudadana local y la intervención del concello (AzCÁRATE, 2009: 97; AlONSO, 2009: 141 y 145).

La red nacional comienza a organizarse en 1944, aunque la idea no era nueva pues ya se había planteado durante la II República (ReVILLA, 2015), localizando los almacenes en los nudos de comunicaciones y cerca de las líneas de ferrocarril, básicas para el transporte de mercancías del momento, en el marco del Plan Nacional de Silos y Graneros (1945). No obstante, la falta de recursos económicos en la posguerra y las carencias de trigo hasta 1952, existiendo pocos excedentes, retrasaron la construcción de las primeras unidades (REviLla, 2015), siendo los primeros levantados los de Valladolid, Villada en Palencia y Alcalá de Henares en Madrid en 1949, aunque el primero inaugurado oficialmente sería el de

7 Los primeros ingenieros encargados de diseñar la red fueron José Real, Leandro de Haro y José María Soroa y Plana bajo la dirección de Carlos Yncenga (AzCÁRATE, 2009: 109). 
Córdoba en 1951, hoy rehabilitado, a los que siguieron los de Mérida (Badajoz), La Roda (Albacete), El Carpio (Córdoba), etc. Edificios que el franquismo «en su afán por mostrar su carácter autoritario», pretendió «dignificar» como otros edificios públicos agrarios, «mediante las directrices de arquitectura tradicional, neohistoricista y neovernácula» (SALAMANCA et al., 2012: 3). Según AzCÁrate (2009: 17), permaneciendo aparentemente invisibles para la esfera arquitectónica española, resultaron a la postre un elemento de gran importancia por sí mismos y por el papel que jugaron en el paisaje rural donde se llegaron a construir 954 unidades: 667 silos verticales (más 2 adquiridos ya edificados), 281 graneros, horizontales o depósitos y 4 intervenciones en castillos. ${ }^{8}$

La red (1949-1990) surge, entonces, como herramienta reguladora (VIDIGAL, 2019: 35), vinculada inicialmente con el Servicio Nacional del Trigo (SNT) creado en 1937 con la finalidad de posibilitar la compra de toda la cosecha de trigo a los agricultores, conservar una reserva nacional para garantizar el consumo con una materia básica, permitir la recepción en puerto de trigo de importación y eventual exportación, y una adecuada manipulación del grano y selección y tratamiento de semillas (FERnÁndez Osuna, 2016: 206). Después dependería del Servicio Nacional de Cereales (SNC) y, más delante, del Servicio Nacional de Productos Agrarios (SENPA), con un intervencionismo cada vez menor, para pasar, finalmente, al Fondo Español de Garantía Agraria (FEGA). En la distribución y localización de unidades se tuvo en cuenta la territorialidad, con un mayor número de unidades en zonas cerealísticas; también se contempló el rol o la función, pues existieron silos y almacenes de recepción (recogían el cereal en las zonas productoras y lo almacenaban hasta su venta o traslado), silos de tránsito y reserva (más grandes, se localizan en centros ferroviarios importantes), y silos de puerto (recibían el cereal por ferrocarril, camión o barco y actuaban como reguladores de la exportación e importación); y, por último, la individualidad, en función de las características propias de cada municipio (AzCÁrate, 2009: 109; SALAZAR, 2015). Su evolución estuvo directamente relacionada con las demandas del campo, las tecnologías constructivas disponibles, los avances en la maquinaria de transporte-elevación y los enclaves concretos (AzCÁRATE, 2002: 59), llegando a contabilizarse más de 950 edificios, hasta que la entrada de España en la Unión Europea y el fin del monopolio estatal les fue dejando sin uso y en situación de progresivo abandono, con continuos cambios de propiedad. En la última etapa, se organizaron en dos redes, una red básica de almacenamiento, más densa en las comunidades autónomas con la mayor producción de granos y con edificaciones más grandes y modernas, y una red secundaria, con unidades más pequeñas y antiguas. En los años 90 la cesión progresiva de silos y graneros se realizó bajo diferentes procedimientos: desafección y cesión a la Dirección General de

\footnotetext{
8 Utilizamos datos extraídos de la obra Catedrales Olvidadas (AzCárate, 2009), siendo conscientes de que varían las estadísticas en función de las clasificaciones realizadas. Así el Grupo de Investigación Silos y Graneros en su web presenta 612 silos de recepción; 279 graneros; 27 macrosilos; 13 silos de selección de semilla; 10 silos de tránsito, 4 castillos y 2 silos de puerto, es decir un total de 945 unidades, algunas ya desaparecidas; mientras que el artículo de FERNÁNDEZ et al. (2017: 298) identifica 952 construcciones, 670 verticales (silos) y 282 horizontales (graneros).
} 
Patrimonio; reversión a los Ayuntamientos que en su día cedieron los terrenos para la construcción; reversión a particulares expropiados al desaparecer la función de utilidad pública que motivó la expropiación; y cesión gratuita en uso a los Ayuntamientos para que decidan sobre su futuro como edificación o como solar municipal. ${ }^{9}$ Hoy muy pocos se encuentran aún en funcionamiento.

Centrándonos en los silos, un total de 667 respondieron a 20 tipologías $^{10}$ identificadas con letras o combinaciones de letras en función de sus características constructivas con variantes y dieron lugar a 35 tipos funcionales diferentes. Algunos se ubicaron cerca de los núcleos rurales, siendo conscientes de su tamaño, otros quedaron aislados en medio de las amplias llanuras cultivadas, buscando los raíles ferroviarios, y otras veces, se localizaron cerca de los núcleos urbanos donde pasaron algo más desapercibidos entre el resto de edificaciones, mientras que solo dos se construyeron a la orilla del mar (AzCÁRATE, 2009: 19 y 225). Generalmente constaban de una torre elevador, básica para el almacenamiento vertical, en cuyo interior se aloja la maquinaria necesaria para subir el grano desde el foso inferior de descarga hasta la parte intermedia o la galería superior horizontal; y una galería superior horizontal de reparto destinada a la distribución horizontal hacia cada celda. ${ }^{11}$ Hoy presentan diferentes situaciones que exponemos a continuación:

1. En algunos casos, ante la falta absoluta de sensibilidad hacia el patrimonio agroindustrial, han sido destruidos como ocurrió con el silo de puerto de Málaga, volado en 2006, un claro ejemplo junto con otros de menor entidad como el de Nájera en La Rioja, de «despilfarro material y cultural» (SoBRINO, 1996: 337). En ocasiones, en ello ha tenido que ver no solo la ausencia de protección y valorización sino el valor del suelo que ocupaban, especialmente en las periferias urbanas.

2. Encontramos numerosos silos y graneros que, una vez perdida la función para la que fueron construidos, están en situación de abandono y precariedad, incluso muchos carecen de protección legal ya que «la especialización les llevó a la muerte» (GARRIDO et al., 2017: 1). Obviamente, dista mucho de lo óptimo pero, al menos, la conservación del elemento en mejor o peor estado alberga esperanza de rehabilitación/reutilización o intervención en el futuro. Puede decirse que «han resistido al desafío del crecimiento de ciudades y al paso del tiempo como hitos tecnológicos de la cultura agraria» (GonZÁlez y RodRíGueZ, 2019: 75). La imagen siguiente (Figura 1) muestra el complejo de silos de Ciudad Real.

9 https://silosygraneros.es/panorama-historico [Consulta: 15/10/2020].

10 Las letras o combinaciones de letras utilizadas fueron: TR, P, A, B, C, D, E, F, GV, H, J, MC, MR, SA, SV, TC, TE, TH, TV, TF, G, GA, SG, SH, X y Z (AzCÁrate, 2009: 114).

11 https://silosygraneros.es/como-funciona-un-silo [Consulta: 15/10/2020]. 


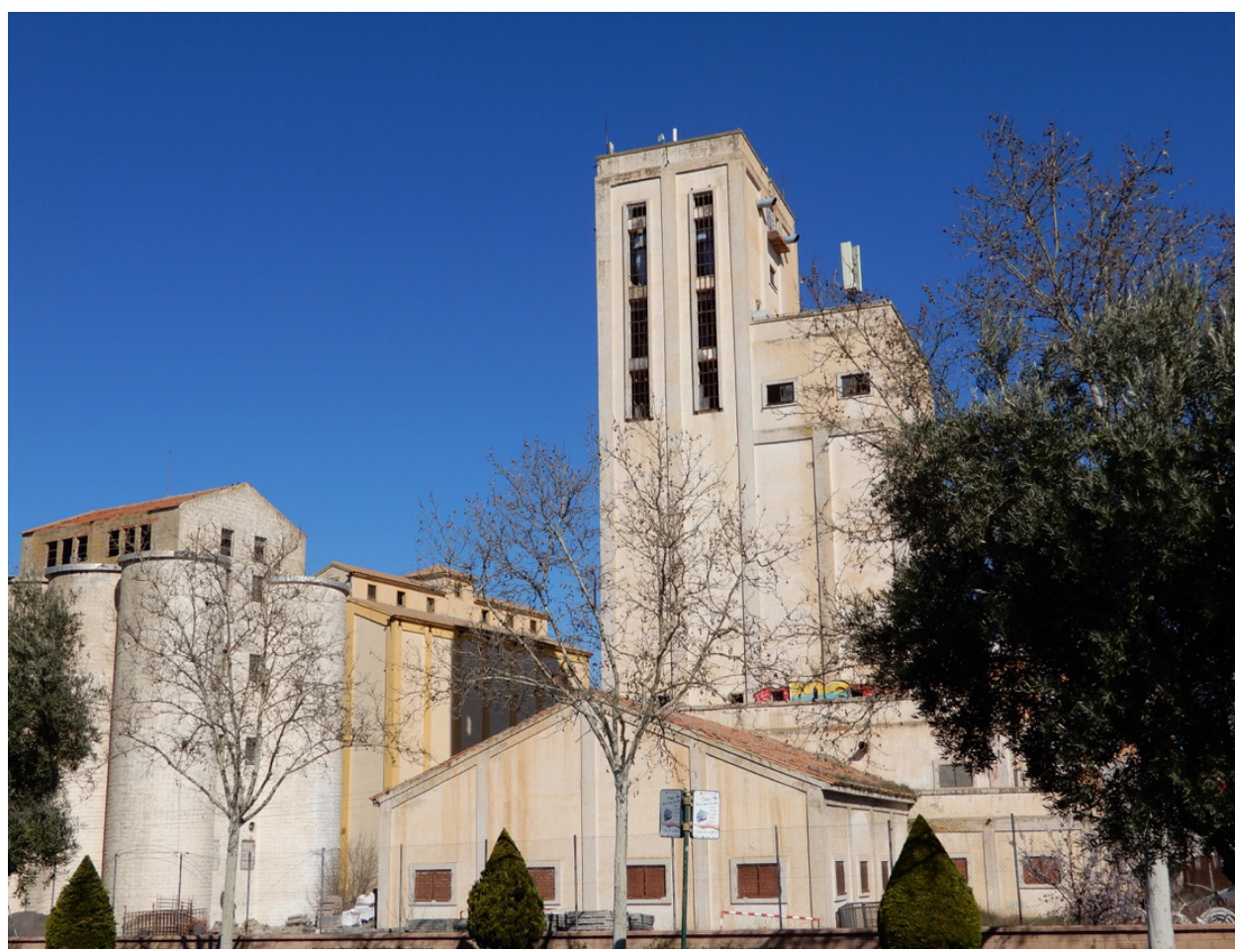

Figura 1. Complejo de silos abandonados en Ciudad Real capital.

Foto: M. Carmen Cañizares (2020).

3. Contamos también con aquellos que mantienen su función, muy pocos en España (desconocemos el número exacto), generalmente cedidos a cooperativas agrarias para su uso y distribución de cereal y, probablemente, con una vida futura corta. Entre ellos se encuentra uno de los que analizaremos en la segunda parte, el silo de La Solana (Ciudad Real).

4. Finalmente, un último grupo lo componen aquellos silos que se mantienen en pie y han sido rehabilitados para ofrecerles un nuevo uso permitiendo conservar el bien y «devolverlo a la vida» adaptándolo a las necesidades de la sociedad actual; o bien, han sido intervenidos contribuyendo a su revalorización. En un contexto en el que el suelo sobre el que se ubicaron inicialmente ha ganado centralidad con el desarrollo demográfico y urbanístico y se ha revalorizado, destacan ciudades y/o barrios en los que se ha conservado el elemento, se ha rehabilitado y se le ha dado un nuevo uso aprovechando una localización más favorable que cuando se construyeron, favoreciendo la resiliencia territorial y la sostenibilidad.

Es este último grupo el que nos parece de mayor interés por cuanto estas actuaciones responden a un intento de «reinventar los edificios que aún permanecen en pie» (SALAMANCA et al., 2012: 7), demostrando que pueden, aún después de los años pasados y el deterioro existente, dar respuesta a unas 
necesidades arquitectónicas para las cuales estas edificaciones no fueron pensadas (MendozA, 2011:5), a partir de usos culturales (teatros, centros de interpretación,..), dotacionales (viviendas), institucionales (administración), etc. Su reutilización supone «en sí una estrategia sostenible ya que se consigue alargar el ciclo de vida de los materiales que lo constituyen y dar al edificio la posibilidad de ser rehabilitado para un nuevo uso». ${ }^{12}$ Algunos ejemplos pioneros encontramos en países como Alemania donde el silo de Daisburg se rehabilitó en 2012 como Contenedor cultural Museo KüpperMühle, Holanda donde en la ciudad de Deventer se rehabilitó el silo de Zwarte como centro de restauración en el que los vendedores ambulantes pueden exponer y vender sus productos (FoodDock); Australia donde en la ciudad de Bunbury un silo de los años 30 del siglo pasado se ha convertido en edificio de apartamentos como también ocurrió con los silos de Dorrego en la capital argentina, Buenos Aires, o los silos de Tervahovi en la ciudad finlandesa de Oulu, entre otros. Junto a ellos, en España, el arquitecto Ricardo Bofill rehabilitó los silos de una antigua fábrica de cementos en St. Just D'esvern (Barcelona) como taller de arquitectura en 1975 (SALAZAR, 2015: 47 y ss.).

En España, algunas iniciativas han contribuido a la revalorización del bien patrimonial, por encima de todo, mientras que en otras ha primado la nueva función sobre el valor patrimonial del edificio. En el primer grupo sobresale, a modo de ejemplo, el de la ciudad de Córdoba, una construcción que combina ladrillo, hormigón y cemento, proyectada por el ingeniero agrónomo Carlos Ynzenga con una capacidad de almacenaje de $15.000 \mathrm{Tm}^{2}$ y estética neomudéjar, que ha sido declarado BIC. en 2015 junto con otros edificios anexos (antigua casa del director, casa del jefe de estación, almacén y caseta de servicios). Con considerable altura, su ubicación junto a la línea de ferrocarril, su empaque, su lograda estética, su imagen unida a la de la ciudad y el hecho de permanecer como un islote respecto a su entorno urbano, lo convierten en un edificio singular que puede contemplarse como colofón de un magno proyecto urbanístico que llevaba a trazar la avenida de Medina Azahara para ensanche y desarrollo de la ciudad. ${ }^{13}$ Hoy, rehabilitado, «se mantiene en buen estado tanto la maquinaria como el edificio y, lejos del abandono, destrucción o expolio que han sufrido otros ejemplares, su uso como depósito del Museo Arqueológico lo ha dotado nuevamente de utilidad, compatible con la conservación del silo como excepcional ejemplo de arquitectura industrial» (JORDANO, 2012: 278).

En el segundo grupo destacamos silos rehabilitados en municipios rurales y urbanos: por ejemplo, para albergar usos dotacionales como el de Trujillo (Cáceres), en el que la zona inferior ha sido reformada para el Centro Integral de Desarrollo «i-Novo Trujillo» como vivero de empresas; el de Alcalá la Real (Jaén) donde las naves laterales del silo se han transformado en Centro de Ocio Juvenil;

\footnotetext{
12 Ver nota 11.

13 Junta de Andalucía (2015): «Decreto 66/2015, de 3 de febrero, por el que se inscribe en el Catálogo General de Patrimonio Histórico Andaluz como Bien de Interés Cultural, con la tipología de Monumento, el inmueble denominado "Silo de Córdoba", en Córdoba», Consejería de Educación, Cultura y Deporte, Sevilla: 1-7. https://www.juntadeandalucia.es/export/drupaljda/cg/acuerdos/Decreto $\% 20 \mathrm{BIC} \% 20$ Silo\%20de\%20C\%C3\%B3rdoba.pdf [Consulta: 15/10/2020].
} 
o el de Pozoblanco (Córdoba) actualmente teatro municipal. También los de Arévalo (Ávila), donde tras una singular rehabilitación su castillo-silo se convirtió en Centro de Interpretación de la Agricultura del Cereal, o el silo de Fuentes de Andalucía (Sevilla) transformado en 2018 en Centro de Recepción de Visitantes y Mirador de la Campiña, complejo sociocultural integrando el propio silo (...) y las naves aledañas como centro juvenil o espacio joven (FERNÁNDEZ OsunA, 2016: 215). Por su parte, usos administrativos destacan en los silos de pequeños municipios extremeños en los que se han convertido en sedes de ayuntamientos como en la Albuera (Badajoz) y en Arroyo de San Serván (Badajoz). Finalmente, destacamos el silo de Alcaracejos (Córdoba), rehabilitado como Balneario y Centro Termal (Centro Termal Los Pedroches) utilizando su planta baja y sus naves laterales.

Como se ha puesto de manifiesto en algunos eventos y publicaciones, los silos conforman una herencia extraña ya que marcan el paisaje en el que están inmersos, bien sea en ciudades, en campo abierto o en las orillas de los puertos, están cargados de una historia reciente visualmente fuerte y sin embargo, «todavía no han movilizado a historiadores, geógrafos, economistas como cabría esperar» (DoréL-FerRé, 2014). Son muchas las dificultades para ofrecerles nuevos usos, dadas sus dimensiones y las enormes necesidades de financiación, principalmente, cuestiones que han contribuido a que muchos se encuentren olvidados o, incluso, hayan desaparecido. En España, «los silos de la Red Nacional no han sido, hasta la fecha, suficientemente valorados ni tampoco han sido objeto especial de estudio u observación particular» (AzCÁRATE, 2009: 227) y no cabe duda de que «estas edificaciones, tan particulares de la península constructivamente hablando, merecen una reinterpretación» (SALAMANCA, 2008: 15). Su actual estado e inactividad pone de manifiesto que pueden ser un hito coordinador de una necesaria revitalización de los paisajes rurales en los que se insertan (GonZÁLEZ y RoDRíGUEZ, 2019: 76) y, quizás, una vía pueda ser la intervención por medio del arte, como veremos en los que presentamos a continuación.

En la Comunidad Autónoma de Castilla-La Mancha hoy se mantienen en pie la gran mayoría de los elementos de almacenamiento agrario construidos bajo los criterios de la Red Nacional. Encontramos localizados en esta región 129 silos y 74 graneros (BARCIELA, 2007), ${ }^{14}$ mayoritariamente sin uso. De ellos, 28 silos y 12 graneros se ubican en la provincia de Ciudad Real, algunos de los cuales se han intervenido como exponemos más adelante; 43 silos y 18 graneros se encuentran en Toledo; 15 silos y 15 graneros en Albacete; 29 silos y 15 graneros en Cuenca; y finalmente, 14 silos y 14 graneros en Guadalajara. Es decir, son las provincias manchegas, especialmente Toledo, Cuenca y Ciudad Real, las que albergan un mayor número de unidades dada su tradición agrícola en el cultivo de cereales.

Nos interesan, en este caso, una parte de ellos, los silos localizados en la provincia de Ciudad Real, un total de 28, de los cuales sabemos que solo uno de ellos mantiene su función, el de La Solana, mientras que el resto están en situación de abandono, siendo frecuentemente utilizados por los ayuntamientos como almacenes municipales. Como ya hemos anunciado, diez de ellos han iniciado un

14 PerIS, D., 2019: «IH 27 los silos rehabilitados», en D2 Arquitectos [en línea]. Disponible en: http:// www.diegoperis.com/ih-24-los-silos-rehabilitados [Consulta: 15/10/2020]. 
proceso de valorización de carácter cultural y turístico mediante la intervención artística en sus muros exteriores, nueve de ellos, o en el interior, como ha sucedido en el silo de Villanueva de los Infantes. Presentamos a continuación el Proyecto Titanes que agrupa estas actuaciones promovido por la Diputación Provincial de Ciudad Real.

\section{EL PROYECTO TITANES (CIUDAD REAL, ESPAÑA)}

La intervención artística a través de la pintura en elementos constructivos de patrimonio industrial agroalimentario constituye una singularidad en España, ya que son muy pocos los ejemplos existentes. Presentamos y caracterizamos, en este caso, un conjunto de silos edificados en el contexto de la Red Nacional anteriormente analizada, hoy mayoritariamente abandonados, que han sido objeto de intervención artística en el seno del Proyecto Titanes.

\subsection{Intervención en silos, antecedentes y génesis del proyecto}

Como en el caso anterior referido a los silos rehabilitados y reutilizados, otros países han ido a la vanguardia en la intervención en silos, en este caso concreto a través del denominado arte urbano o street art, entendiendo que las pinturas exteriores y/o interiores no siempre conllevan la rehabilitación del elemento y la concesión de un nuevo uso. Además, dado que el concepto de arte urbano puede ser amplio, nos referimos a intervenciones murales pictóricas realizadas en lugares, como sucede con esta tipología, «no neutros, cargados con valores históricos, espaciales, sociales...» (HERRERA, 2011:17). En el panorama internacional, destacamos iniciativas localizadas en países como Italia, donde la ciudad de Catania (Sicilia) albergó en 2015 el Emergence Festival Project "Street Art Silos" con intervenciones en silos históricos de ocho artistas internacionales (entre ellos los españoles Okuda y Rosh333); y Australia donde, también en 2015, artistas locales y foráneos intervinieron 25 silos de grano a lo largo de $200 \mathrm{~km}$ atravesando varios estados, unidos en un mismo sendero, Silo Art Trail, que se ha convertido en una atracción turística, especialmente en algunos estados como Victoria (TsAKONAS, 2019). En España son aún muy pocos los ejemplos existentes, entre ellos, la intervención del artista holandés Guido Van Helten en los antiguos depósitos de hormigón en las Bodegas Solar de Samaniego en Laguardia (Rioja), los silos de la Cooperativa d'Ivars, planta de fabricación de piensos de Torregrossa, en el Pla d'Urgell (Lleida), con la obra mural más grande de Cataluña realizada por los artistas Jofre Oliveras y Nil Safont (SliM), y los silos metálicos pintados de la Fábrica de Cervezas La Zaragozana en Zaragoza, tanques de fermentación que sustentan la obra de Miguel Wert.

Localizados en nueve municipios de la provincia de Ciudad Real (Castilla-La Mancha), diez silos que en su día pertenecieron a la Red Nacional y actualmente han perdido su función (en todos los casos excepto en uno), han sido intervenidos 
a través del arte en el seno del Proyecto Titanes, ${ }^{15}$ promovido por la Diputación Provincial. Su título identifica estas construcciones con «titanes» que han resistido el paso del tiempo después de haber tenido un uso agrario muy intenso, a la vez que brindan «homenaje a los orígenes como provincia vinculada al sector agrario, a la historia y las tradiciones». ${ }^{16}$ Un proyecto cultural e inclusivo iniciado en abril de 2019 y en el que está previsto actuar sobre un total de 20 silos que ha contribuido a renovar la imagen de estos elementos con valor patrimonial y los ha sacado del olvido concediéndoles cierto protagonismo. Precisamos, no obstante, que no han sido objeto de rehabilitación, ni de reutilización (nuevos usos), sino de intervención en sus muros exteriores, preferentemente, previas labores de regeneración (limpieza y mantenimiento) y como tal deben ser entendidos. El proyecto, sin duda, constituye una de las iniciativas más destacables a la hora de combinar valorización del patrimonio industrial agroalimentario y arte urbano. En este caso, como en el de otras actuaciones de este tipo en edificios civiles (viviendas, faros,...), equipamientos (piscinas,...) o religiosos (iglesias desacralizadas,...), el arte urbano o street art, también denominado arte callejero, persigue el objetivo de «interpretar y/o decorar el contexto» (GARCíA GAYO, 2019: 154) a partir de una intervención, acción diferente a los graffiti en los que sus autores buscan dejar su seña de identidad a través de una firma.

Como antecedentes del proyecto sobresalen dos actuaciones realizadas en 2018 en municipios de la provincia de Ciudad Real: la intervención sobre el mural de la piscina municipal de Puertollano (Figura 2, izqda.) llevada a cabo con gran éxito por Okuda San Miguel y la intervención en el silo de Almagro (Figura 2, dcha.) a cargo del artista local Antonio Laguna, así como su rehabilitación interior como Centro Cultural para albergar las celebraciones del 40 aniversario del Festival Internacional de Teatro Clásico y, actualmente, mantener la actividad cultural (sala de baile,...).

15 https://iamtitanes.com [Consulta: 15/10/2020].

16 Redacción Ciudad Real, 2020: «El proyecto de arte mural "Titanes" pone así de chulos varios silos de Ciudad Real», en EnTomelloso.com [en línea]. Disponible en: https://entomelloso.com/noticias/ sociedad/el-proyecto-de-arte-mural-titanes-pone-asi-de-chulos-varios-silos-de-ciudad-real [Consulta: $15 / 10 / 2020]$. 

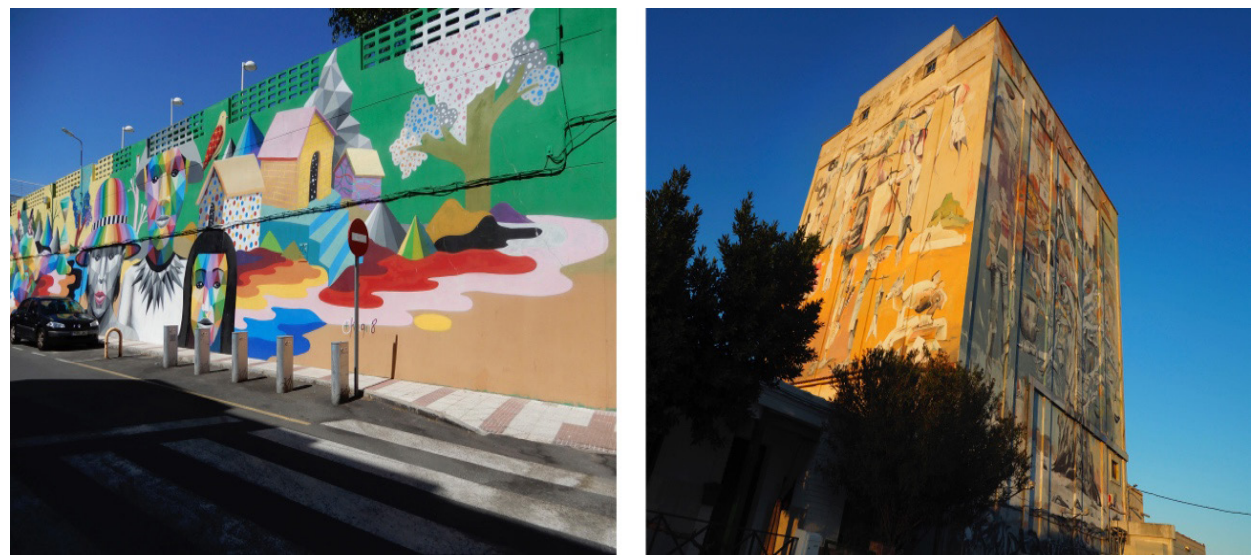

Figura 2. Mural de la piscina municipal de Puertollano (izquierda) y Silo de Almagro (derecha). Fotos: M. Carmen Cañizares (2020).

El Proyecto surge bajo el auspicio institucional de la Diputación Provincial de Ciudad Real con «la intención de poner en valor el talento de las personas con discapacidad y revalorizar el entorno rural» (Diputación, 2020) y una financiación inicial de 400.000 euros, promovido por el colectivo de artistas «Ink and Movement», al frente del cual se encuentra Okuda San Miguel (Óscar San Miguel Erice), comisario y artista santanderino internacionalmente reconocido. Especialmente relevante es la colaboración con el colectivo «Laborvalía», asociación para la inclusión social de personas con discapacidad, que agrupa los Centros Ocupacionales de la provincia de Ciudad Real, ya que, en las pinturas murales, han colaborado 500 personas coordinadas por 50 monitores, demostrando que el arte puede ser una vía de inclusión. ${ }^{17}$

\subsection{Silos intervenidos en el Proyecto Titanes a través del arte urbano}

El conjunto de artistas encargado de intervenir los silos ya realizó hace 15 años el Urban Art Canarias como primer evento de arte público de gran formato, y ha pretendido ahora conformar un proyecto artístico y social sobre las grandes paredes de los silos que permita celebrar el trabajo conjunto. Junto a Okuda San Miguel que ha transformado el Silo de Calzada de Calatrava y el interior del Silo de Villanueva de los Infantes, han participado artistas como Demsky y Smithe (Silo de Corral de Calatrava), Fitan Magee (Herencia), Bicicleta Sem Feio (La Solana), colectivo Hell'O (Malagón), Equipo Plástico (Manzanares I), Daniel Muñoz y Spok Brillor (Manzanares II), Nychos (Porzuna) y Ricardo Cavolo (Campo de Criptana). Cada uno de ellos generó un trabajo pensado para un silo concreto y hoy queda constancia no solo del autor/es, sino del significado conceptual de la 17 http:/ /laborvalia.es [Consulta: 15/10/2020]. 
obra a través de una placa informativa. La elección de los silos está relacionada con el carácter que estas grandes infraestructuras ofrecen, en mitad de espacios llanos con una visualización óptima desde la lejanía, la historia que tienen detrás, para lo que fueron creados y en lo que se han convertido ${ }^{18}$ (RUIZ DE LA PRADA, 2020: 4-5).

Destacamos aquellos localizados en áreas urbanas, como las ciudades de Manzanares, La Solana y Campo de Criptana, a los que se unirá la capital, Ciudad Real, y Alcázar de San Juan en una segunda fase, aunque la mayor parte se localizan en núcleos semirurales (Herencia, Malagón, Villanueva de los Infantes, Calzada de Calatrava y Porzuna), e incluso rurales (Corral de Calatrava), como podemos observar en la Tabla 1. En realidad, son asentamientos de población que reflejan la conexión urbano-rural en este territorio donde el componente de ruralización es aún evidente. Todos ellos, pertenecientes a la red secundaria, son silos de recepción cuya función era recoger la cosecha en las áreas productoras de cereal y almacenarla hasta su venta o traslado, generalmente por camiones o ferrocarril.

TABLA 1

Localización y características de los silos incluidos en 2020 dentro del Proyecto Titanes

(Ciudad Real, España)

\begin{tabular}{|c|c|c|c|c|c|}
\hline Población & $\begin{array}{c}\text { Habitantes } \\
\text { (2019) }\end{array}$ & $\begin{array}{l}\text { Tipo de silo y año } \\
\text { de construcción }\end{array}$ & $\begin{array}{c}\text { Capacidad } \\
\qquad\left(\mathrm{Tm}^{2}\right)\end{array}$ & $\begin{array}{c}\text { Artista } \\
\text { (Intervención) }\end{array}$ & Fecha \\
\hline $\begin{array}{l}\text { Calzada de } \\
\text { Calatrava }\end{array}$ & 3.719 & (E) Recepción 1983 & 5.000 & $\begin{array}{c}\text { Okuda San } \\
\text { Miguel }\end{array}$ & abril 2019 \\
\hline $\begin{array}{l}\text { Corral de } \\
\text { Calatrava }\end{array}$ & 1.123 & (E) Recepción 1983 & 5.000 & Demsky y Smithe & abril 2019 \\
\hline La Solana & 15.479 & (D) Recepción 1968 & 2.630 & Bicicleta Sem Feio & abril 2019 \\
\hline Manzanares & 17.997 & $\begin{array}{l}\text { (C) Recepción } 1955 \\
\text { (D) Recepción } 1964\end{array}$ & $\begin{array}{l}2.150 \\
3.300\end{array}$ & $\begin{array}{l}\text { I. Equipo Plástico } \\
\text { II. Spok Brillor }\end{array}$ & abril 2019 \\
\hline Malagón & 7.998 & (D) Recepción 1955 & 1.900 & Colectivo Hell'O & abril 2019 \\
\hline Herencia & 8.390 & (D) Recepción 1967 & 1.400 & Fitan Magee & mayo 2019 \\
\hline Porzuna & 3.532 & (E) Recepción 1970 & 4.700 & Nychos en & julio 2019 \\
\hline $\begin{array}{l}\text { Campo de } \\
\text { Criptana }\end{array}$ & 13.414 & (D) Recepción 1966 & 2.175 & Ricardo Cavolo & octubre 2019 \\
\hline $\begin{array}{l}\text { Villanueva } \\
\text { de los } \\
\text { Infantes }\end{array}$ & 4.935 & (C) Recepción 1954 & 1.650 & $\begin{array}{c}\text { Okuda San } \\
\text { Miguel }\end{array}$ & octubre 2019 \\
\hline
\end{tabular}

Fuente: Elaboración propia a partir de AzCÁRATE, 2009 y https:/ / silosygraneros.es

18 Ruiz De LA PRADA, S., 2020: «Titanes», el proyecto de arte urbano que pone a Ciudad Real en el punto de mira», en Harper's Bazaar [en línea]. Disponible en: https://www.harpersbazaar.com/es/cultura/viajes-planes/a30121969/titanes-proyecto-arte-urbano-ciudad-real-street-art-okuda [Consulta: $15 / 10 / 2020]$. 
Las tipologías de los silos incluidos en el proyecto responden a las letras $\mathrm{C}$, $\mathrm{D}$ y E, tres de las 20 diseñadas inicialmente, que presentan algunas pequeñas diferencias entre ellas, aunque las tres fueron creadas para el almacenamiento vertical de grano. Sus características principales son las siguientes (SALAMANCA, 2008: 81-85): 1. Los silos Tipo $C$ se identifican por celdas de sección circular sin muro exterior, cuyas paredes trabajan con leyes de presiones continuas, así como con afán de reducir maquinaria con las celdas en el plano de apoyo del edificio, que normalmente solía quedar un metro y medio por encima del suelo. La planta de maniobra se sitúa entre las celdas circulares, sin disponer de celdas intermedias sobre el pasillo de maniobra, mientras que la torre (o elevador) puede estar situada en el frontal del edificio sobresaliendo del resto de las celdas o bien en el espacio que queda entre las filas paralelas de celdas, además, no disponen de tren vertical de selección. 2 . Los silos de Tipo $D$ son los más extendidos y surgen como evolución de otros anteriores (A y B), con muy poca ornamentación exterior y celdas cuadrangulares, la mayor parte disponen de cubierta inclinada con pequeñas mansardas junto a la galería horizontal superior para poder acceder a las celdas laterales exteriores. Las filas de celdas laterales dejan un pasillo central de maniobra sobre el cual se sitúa otra fila de celdas de menor dimensión en altura por encontrarse elevadas. Por su parte, la torre se sitúa en el frontal del edificio, quedando diferenciado de estas desde el exterior y en altura. Tampoco disponen de tren vertical de selección, es decir, todo el grano sube hasta la galería superior (Figura 3). 3. Finalmente, los Tipo E tienen mayor capacidad y surgen como adición de dos elevadores tipo $\mathrm{D}$ unidos por una fila de celdas exteriores y suprimiendo una de ellas. Creados para almacenar una mayor cantidad de cereal, tienen dos filas de celdas y dos galerías de maniobra, además, todas las filas de celdas laterales y centrales se apoyan sobre el terreno dejando dos pasillos centrales paralelos de maniobra sobre los cuales se sitúa otra fila de celdas de menor dimensión en altura por encontrarse elevadas. Como podemos observar (Tabla 1), en general, aquí predominan los de pequeñas dimensiones con capacidades que oscilan entre las $5.000 \mathrm{Tm}^{2}$ de los dos más grandes (tipología E), construidos a partir de 1970, hasta las 1.650, el más pequeño. Morfológicamente, las diferencias más evidentes las encontramos entre los compactos rectangulares (tipologías D y E) frente a los compuestos por varios cilindros fruto de las celdas circulares (tipología C). 


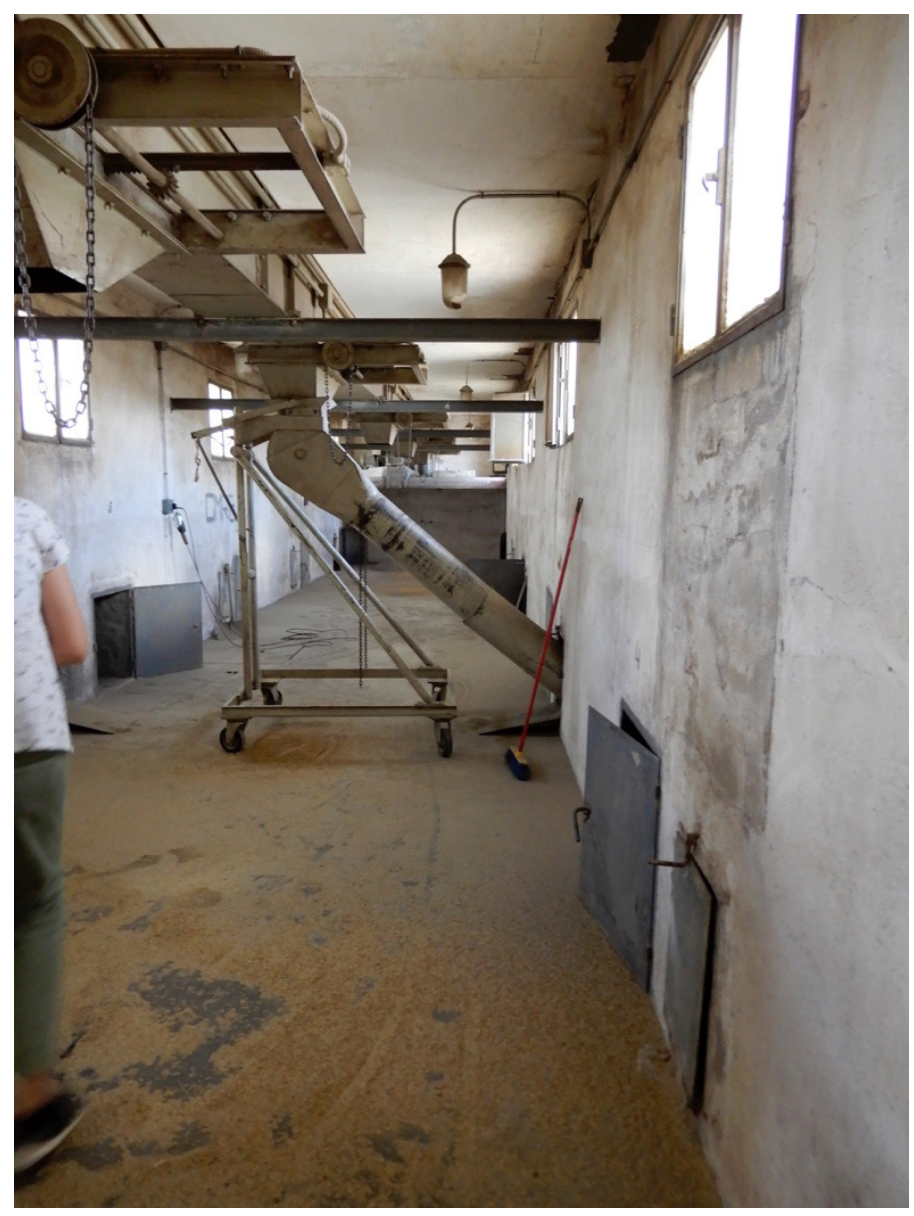

Figura 3. Interior del Silo de La Solana (galería central de maniobra superior).

Foto: M. Carmen Cañizares (2020).

Presentamos brevemente, a continuación, las características de la intervención en cada uno de los silos siguiendo la información contenida en la web del proyecto. Mayoritariamente son exteriores (paredes o muros de los silos), lo cual permite que la obra se pueda ver incluso a distancia, excepto el de Villanueva de los Infantes cuya intervención se realiza en el interior. Comenzamos por uno de los más representativos, el Silo de Calzada de Calatrava (Figura 4, izqda.), una de las intervenciones más relevantes, realizada por el propio comisario del proyecto bajo el epígrafe de Legends from La Mancha, en colaboración con la Asociación Caminar, el equipo Valorarte y la Asociación Fuensanta. Con guiños a películas de Pedro Almodóvar, nacido en este municipio, como La mala educación y La flor de mi secreto, al Quijote y a la orden de los templarios, la obra de Okuda (Santander, 
España) posiciona a este enclave como destino preferente del museo al aire libre que quiere ser Ciudad Real. ${ }^{19}$ Por su parte, en el Silo de Corral de Calatrava (Figura 4, dcha.) de Demsky (Elche, España) y Smithe (México DF, México), con la denominación Parábolas del Pensamiento, los artistas, en colaboración con la Asociación Fuente Agria y el Centro Ocupacional Xabeca, han pretendido unificar su estilo basándose en las fases del cerebro a la hora de crear y pensar. Su localización en la entrada sur de la localidad le concede cierto protagonismo.
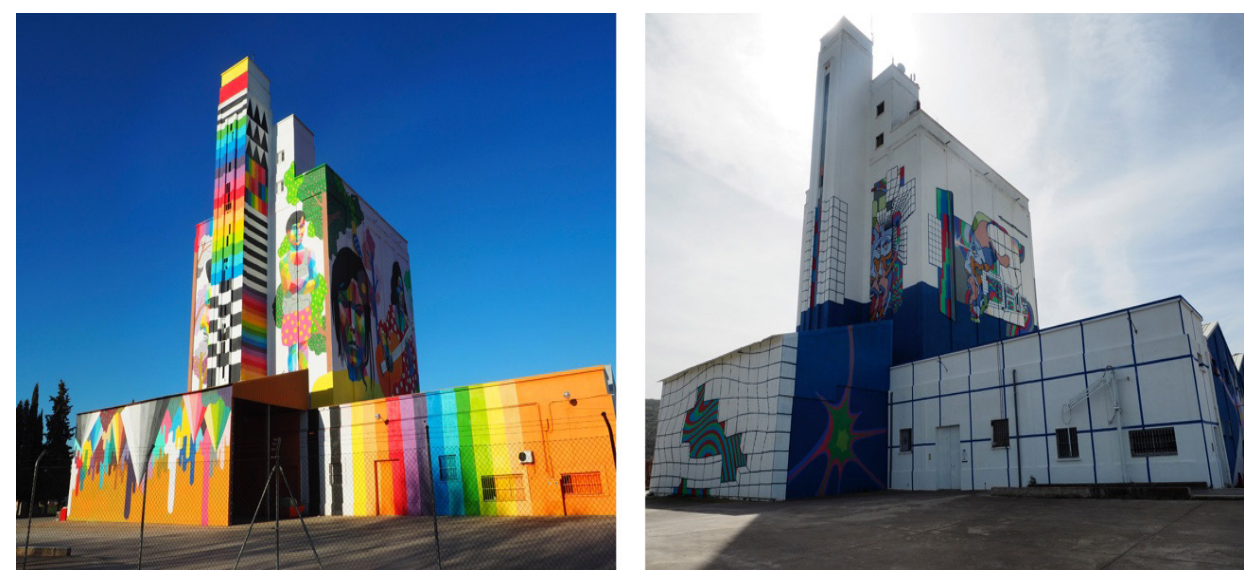

Figura 4. Silo de Calzada de Calatrava (izquierda) y Silo de Corral de Calatrava (derecha). Foto: M. Carmen Cañizares (2020).

El Silo de Herencia (Figura 5, izqda.), por su parte, obra de Fitan Magee (Lismore, Australia) en colaboración con el Centro El Picazuelo de Herencia y el equipo Valorarte, con el título House of Giants, refleja personas reales, dos trabajadores sociales y un chico, miembros de Laborvalía, para resaltar el carácter social del proyecto. El clima y el paisaje local también tienen cierto protagonismo para el artista que afirmó: «hay algo ensoñador en espacios abiertos y vacíos como este» (Diputación, 2020). El Silo de La Solana (Figura 5, dcha.) del brasileño Bicicleta sem Freio (Goias, Brasil), Os Gigantes de la Mancha, junto con la Asociación Virgen de Peñarroya de La Solana, la Asociación ADIN, el equipo Valorarte y la Asociación AFAD, representa el poder de la creatividad e imaginación y su rol indispensable en la habilidad de los seres humanos para dar sentido al mundo, especialmente los niños con discapacidad intelectual. Es este uno de los pocos en funcionamiento en España, propiedad del Ayuntamiento aunque cedido a una cooperativa agraria.

19 Robles, J.M., 2019: «Arte urbano en la España vacía. Así quiere ser Ciudad Real un museo al aire libre», en El Mundo [en línea]. Disponible en: https://www.elmundo.es/cultura/2019/04/12/ 5caf788d21efa0d0078b45d1.html [Consulta: 15/10/2020]. 

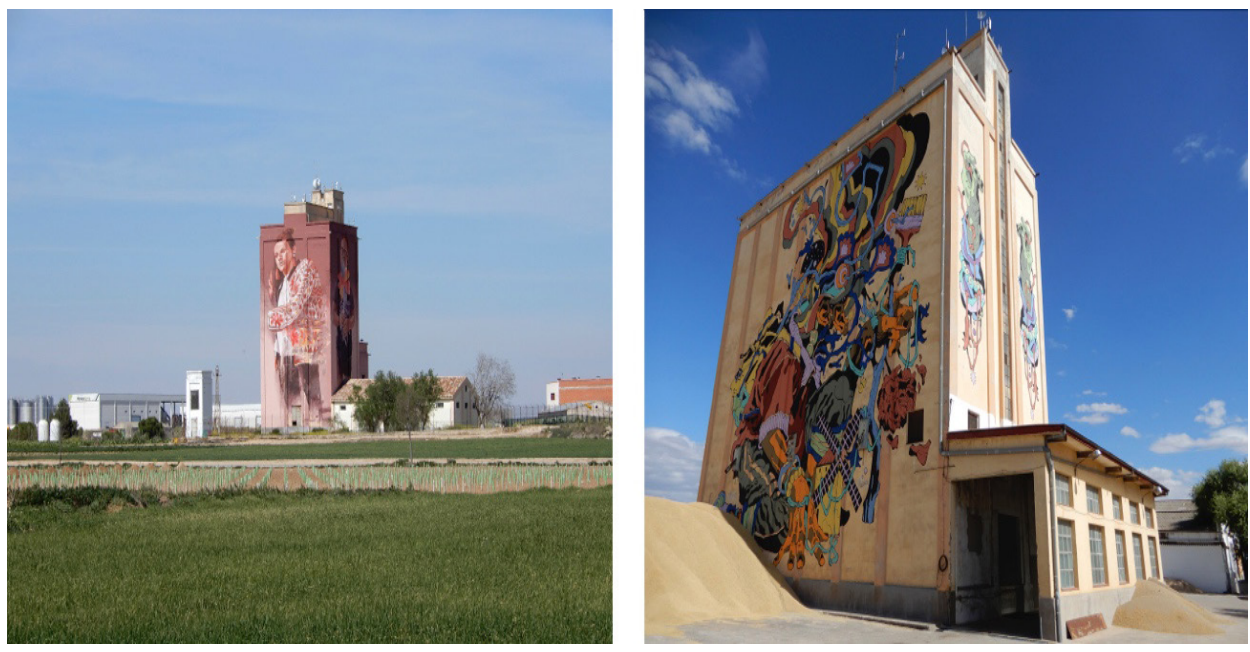

Figura 5. Silo de Herencia (izquierda) y Silo de La Solana (derecha). Foto: M. Carmen Cañizares (2020).

En el Silo de Malagón (Figura 6, izqda.) la idea del colectivo Hell'O (Bruselas, Bélgica) en colaboración con la Asociación Coraje y el equipo Valorarte, fue mezclar, en Untitled, formas abstractas y elementos figurativos en un entorno colorido, así como jugar con el equilibrio entre las diferentes formas y encontrar una composición homogénica, buscando un toque optimista, pop y fresco que alcance a todo el mundo. En el Silo de Porzuna (Figura 6, dcha.), sin embargo, Nychos (Styria, Austria) en The Pillar of unified love, junto con la Asociación Coraje Malagón, el Centro Ocupacional El Robledo y el equipo Valorarte, buscó que el esqueleto, humano y animal, fuera protagonista de la intervención en relación con el miedo a la muerte, una característica muy humana. Además, el artista austriaco quiso aprovechar sus recientes investigaciones y experiencias personales sobre el cuerpo físico, la conciencia y la espiritualidad para descontextualizar nuestro concepto de la muerte, ya que para él no hay lugar para el miedo a la muerte pues el amor es todo e infinito. 

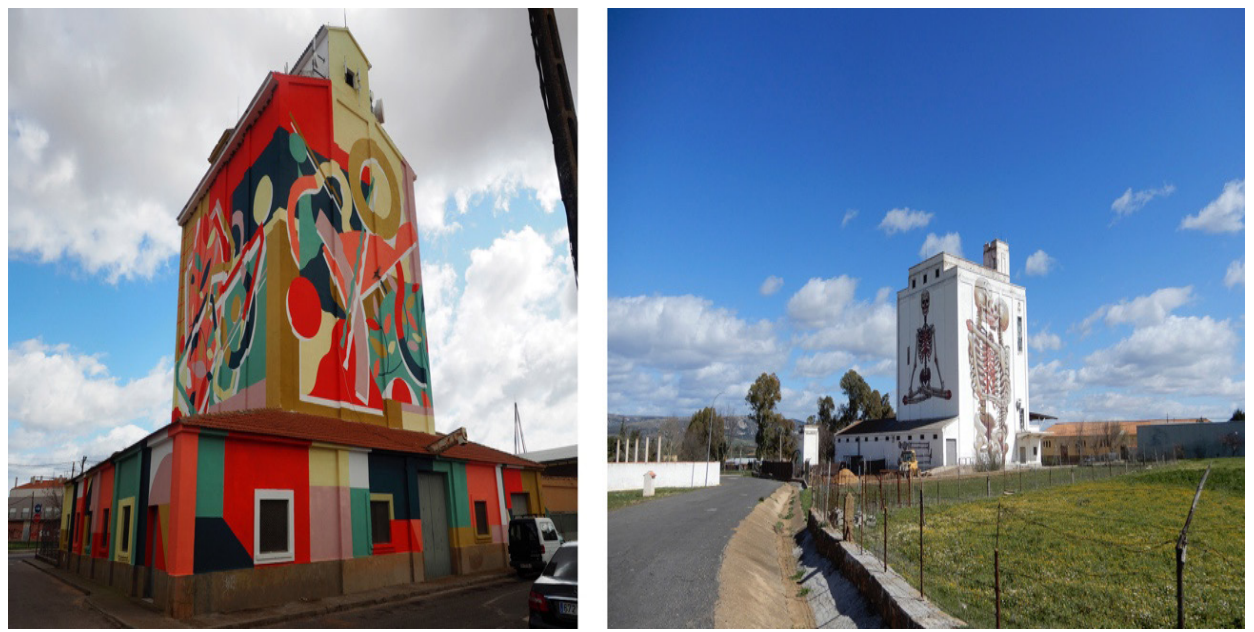

Figura 6. Silo de Malagón (izquierda) y Silo de Porzuna (derecha).

Fuente: M. Carmen Cañizares (2020).

Por su parte, la ciudad de Manzanares alberga un complejo de silos, concretamente dos de diferente tipología, que han sido intervenidos independientemente. El Silo Manzanares I (Figura 7) es obra del Equipo Plástico compuesto por los artistas Eltono (París, Francia), Nano 4814, Nuria Mora y Sixe Paredes (Madrid, Barcelona y Vigo, España). Realizado en colaboración con el Centro de Ocupación de Manzanares y bajo el apelativo Meseta constituye un homenaje al campo, al inabarcable espacio que rodea estos silos. Las tonalidades y patrones de las tierras colindantes, sus texturas y matices cubren como un manto cada centímetro de muro, dando al edificio un carácter rotundo, casi escultórico. En palabras de sus autores «ignorando los límites del edificio, camuflándolo simbólicamente en su entorno, no hacemos sino acentuar su actual invisibilidad, tras tantos años en desuso, y en cierto modo aligeramos el peso de su historia» (Diputación, 2020). En el caso del Silo Manzanares II (Figura 7), Untitled, Daniel Muñoz (Moraleja, España) y Spok Brillor (Madrid, España), en colaboración con el Centro de Ocupación de Manzanares, plantean varias líneas conceptuales en su intervención. Por un lado, representa la celebración de 15 años de colaboraciones artísticas y personales juntos: cada medalla simboliza una anécdota surgida de algunos de los proyectos realizados. Por otro lado, reafirma el edificio desde un punto de vista arquitectónico, se «condecora» el silo, no se «decora» ya que les parecía importante reafirmar el objeto en sí y no su historia política. Y, por último, la idea del oro aporta ironía debido a que es lo opuesto al pan, como producto de primera necesidad que salía del silo y que en realidad, siempre se representó como algo lumínico y poderoso en toda la imaginería del siglo xx. Es un guiño, también, al posible futuro uso del edificio en relación con las actividades deportivas. 


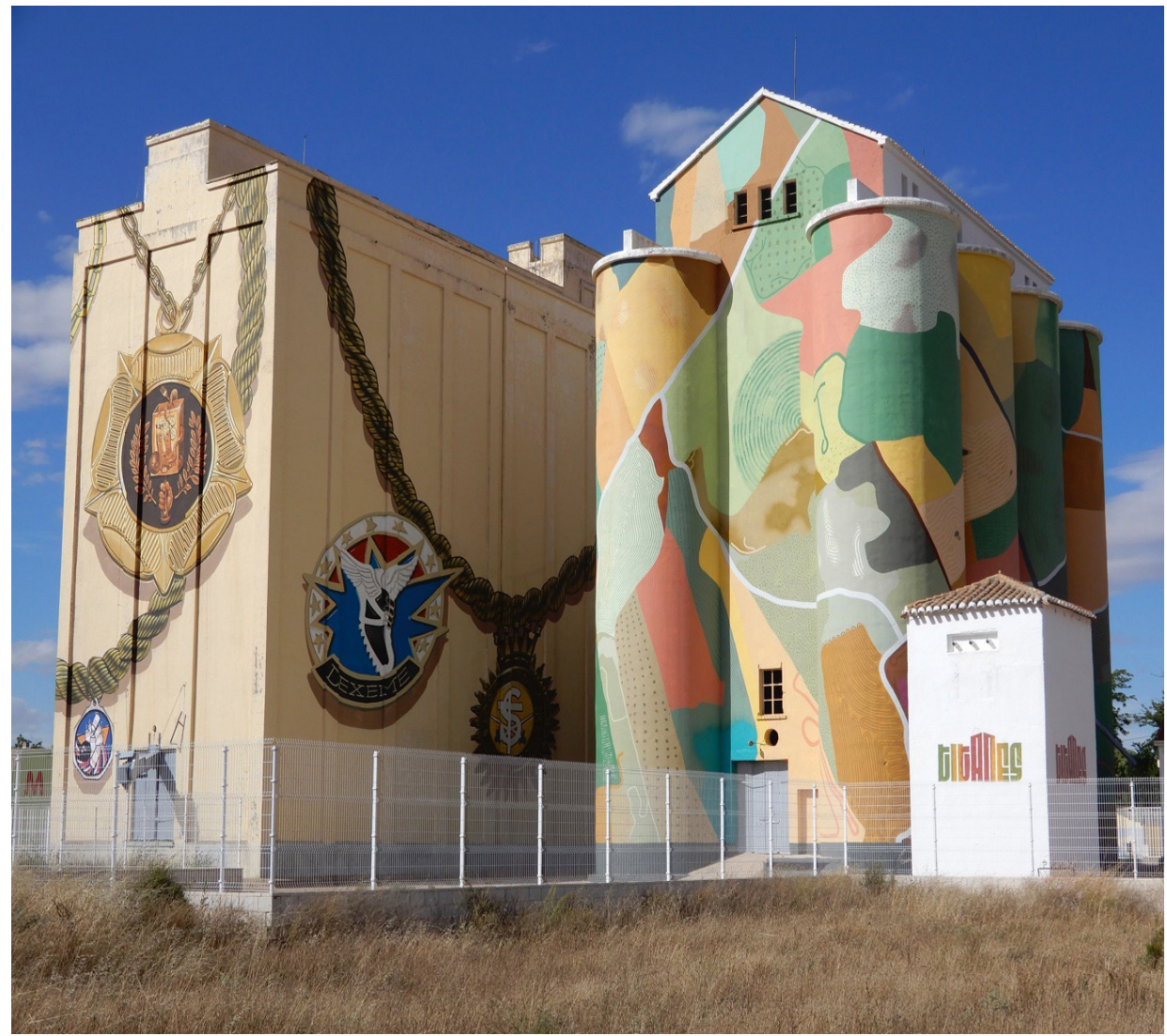

Figura 7. Complejos de Silos de Manzanares I (derecha) y II (izquierda). Fuente: M. Carmen Cañizares (2020).

Finalmente, en octubre de 2019 se intervinieron las dos últimas construcciones hasta el momento. En el Silo de Campo de Criptana (Figura 8), el artista Ricardo Cavolo (Salamanca, España) en colaboración con el Centro Ocupacional de Campo de Criptana, Aspana Campo de Criptana y el equipo Valorarte, ha buscado representar la lucha interior contra los fantasmas que tenemos cada uno de nosotros, que dejamos que habiten en nuestra mente y de ahí su denominación, La Lucha. Como aquellos gigantes que Don Quijote ve en los molinos, la niña pintada nos representa a todos en esa lucha, a espada contra los fantasmas. Una batalla que ella ganará porque el hecho de ponerse a combatir esos fantasmas 
es ya una gran victoria. Finalmente, el Silo de Villanueva de los Infantes (Figura 9) ha sido intervenido, de nuevo, por Okuda San Miguel en su interior (no en los muros), aportando sus características formas geométricas con el título de Universal church, en colaboración con la Asociación ADIN Villanueva de los Infantes y el Equipo Valorarte. Buscando expresar un mosaico universal de banderas de países inexistentes en el que todos somos uno, su particularidad es que constituye uno de los pocos ejemplos a escala mundial con estas características. Ello, sin duda, le ofrece un mayor potencial para revitalizar el entorno urbano en el que se encuentra, así como el propio núcleo de población, con consolidado atractivo turístico, como Conjunto Histórico, dentro de la provincia.

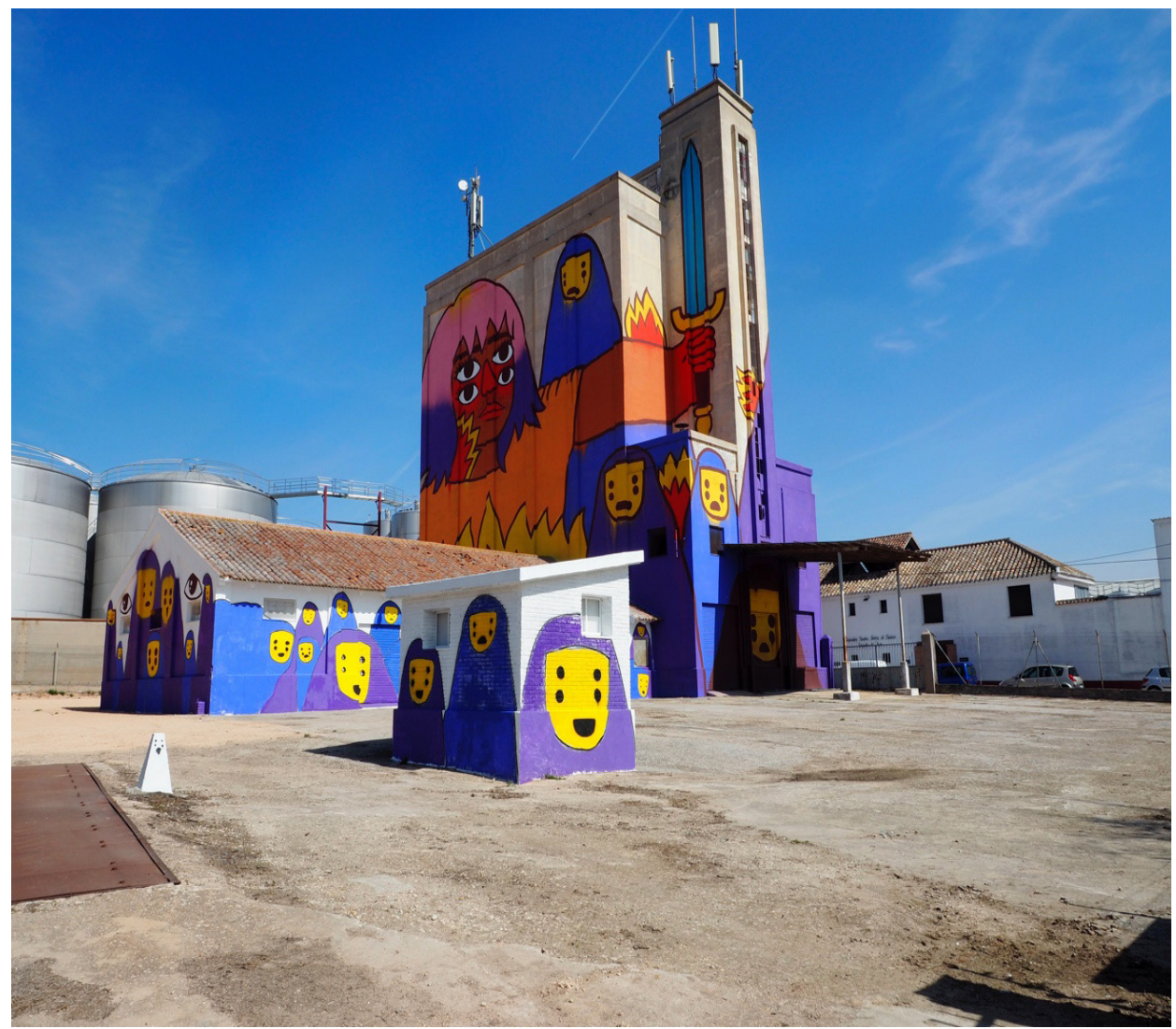

Figura 8. Silo de Campo de Criptana. Foto: M. Carmen Cañizares (2020).

Como en el caso de otros territorios, lo importante es «convertir estos elementos en motores del desarrollo local» (BOCANEGRA, 2016: 19), además de ser «aval de otros proyectos/iniciativas que promueven la defensa y salvaguarda de este patrimonio» (BOCANEGRA y RODRíGUEZ, 2016: 230). De momento, su repercusión 
no es solo local o regional, sino también nacional e incluso internacional pues la web de viajes de National Geographic se ha hecho eco de ellos, ${ }^{20}$ han sido visitados por artistas y expertos (Martha Cooper), objeto de publicaciones en el diario británico The Guardian con el reportaje fotográfico Spain hosts world's largest openair museum, afirmando que esta iniciativa «convierte a la tierra de Don Quijote en un proyecto de arte gigante», ${ }^{21}$ o documentales como el de la cadena americana CNN dentro en su canal temático Great Big Story. Añadimos la presentación de la «Ruta de los Silos» como producto turístico en la última Feria Internacional de Turismo (FITUR), en enero de 2020, promocionando $20.000 \mathrm{~km}^{2}$ de arte mural inclusivo $^{22}$ (YÉBENES, 2020: 1-2).

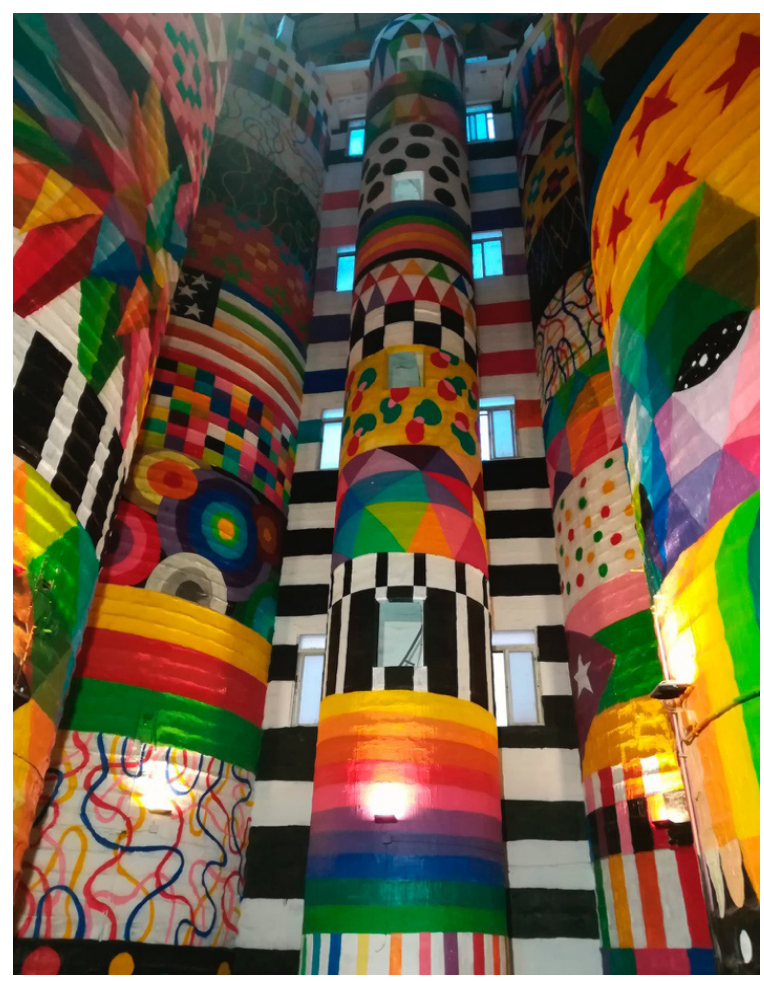

Figura 9. Interior del Silo de Villanueva de los Infantes. Foto: Ayuntamiento Villanueva de los Infantes (2020).

20 SANTOS, N., 2019: «Street Arte y costumbrismo. Algo surrealista está pasando en los silos manchegos», en Nationalgeographic.com [en línea]. Disponible en: https://viajes.nationalgeographic.com. es/a/street-art-grafitis-silos-ciudad-real_14060 [Consulta: 15/10/2020].

21 GARCíA-DonAs, C. y Po, E., 2019: «Spain hosts world's largest open-air museum», en The Guardian en línea]. Disponible en: https://www.theguardian.com/travel/gallery/2019/apr/26/titanes-projectla-mancha-spain-world-largest-open-air-at-museum-in-pictures [Consulta: 15/10/2020].

22 YÉBENES, J., 2020: «Ciudad Real promociona 20.000 kilómetros cuadrados de arte mural inclusivo», en Lanzadigital en línea]. Disponible en: https://www.lanzadigital.com/provincia/ciudad-real-promociona-20-000-kilometros-de-arte-mural-inclusivo Consulta: 15/10/2020]. 


\section{CONCLUSIONES}

Los valores acumulados a lo largo del tiempo por los silos en España hacen de ellos unos de los bienes más significativos del patrimonio industrial agroalimentario, además de excelentes muestras de arquitectura industrial, paradójicamente realizada por ingenieros, preferentemente. La existencia de más de 650 unidades construidas en el seno de la Red Nacional de Silos y Graneros (1944-1990), mayoritariamente abandonadas (algunas desaparecidas), ofrecen una enorme potencialidad para su valorización, como ha quedado demostrado con algunos ejemplos de aquellos que se han reinventado con nuevos usos como museos, teatros, centros administrativos o espacios para jóvenes. Su distribución territorial, tanto en zonas urbanas, los menos, como rurales, la mayoría, realza su vinculación con el paisaje y pone el acento en el contraste que supone la importancia que alcanzaron en relación con el tratamiento de los productos agrarios (cereales), su distribución en la España franquista y los cambios socioeconómicos de mediados del siglo xx, incluido el propio desarrollo del país, frente a la escasa atención institucional que se les ha prestado hasta el momento, a pesar de los valores que atesoran.

En este contexto y como conclusión más destacada, el Proyecto Titanes iniciado en 2019 con la intervención de 10 silos en 9 municipios de la provincia de Ciudad Real (Castilla-La Mancha, España) conforma un ejemplo singular de valorización del patrimonio industrial agroalimentario a través del arte urbano, principalmente de pinturas murales exteriores. Un proyecto inclusivo, por la colaboración de personas con capacidades distintas que, con el objetivo de vincular inclusión social y revalorización de los entornos rurales, ofrece potencialidades para reactivar el turismo de interior. Devuelve el protagonismo a estas unidades de almacenamiento que forman parte de la memoria de un territorio y de la identidad de sus gentes, además de asegurar su conservación para las generaciones futuras. Obviamente, solo es un primer paso para su valorización, en algunas ocasiones discutida por acomodarse más o menos a las tradiciones locales. Una vez que se les ha concedido atención, adjudicarles un nuevo uso permitiría rehabilitarlos completamente y asegurar su supervivencia, algo aún complicado.

\section{RECURSOS WEB}

Grupo de Investigación Silos y Graneros, https:/ / silosygraneros.es

Lavorbalía, http:/ / laborvalia.es

Proyecto Silos, http:/ / www.proyectosilos.com

Proyecto Titanes, https://iamtitanes.com 


\section{REFERENCIAS}

Alonso, J.R. (2009): «El patrimonio industrial en Galicia en los albores del siglo XXI», LIÑO. Revista Anual de Historia del Arte, 15: 139-147.

Álvarez, M.A. (Ed.) (2009): Patrimonio Industrial Agroalimentario. Testimonios del diálogo intercultural, CICEES, Gijón.

AzCÁrATE, C.A. (2002): «Los silos de cereal en España. ¿Arquitectura? Industrial de la España Rural», en Coloquio Arquitectura, ciudad e ideología antiurbana, Universidad de Navarra, Pamplona: 55-62.

AzCÁrAte, C.A. (2009): Catedrales olvidadas: la red nacional de silos en España (19491990), T6 Ediciones, Pamplona.

Barciela, C. (2007): «Ni un español sin pan»: la Red Nacional de Silos y Graneros, Prensas Universitarias de Zaragoza, Zaragoza. http://dx.doi.org/10.26754/ uz.978-84-7733-964-9.

Blanco, S.; Río, A.S. (2015): «La fábrica como escenografía, la puesta en escena del patrimonio industrial», en M.A. Álvarez (ed.), Espacios industriales abandonados, gestión del patrimonio y medio ambiente, CICEES, Gijón: 229-235.

BoCANEGRA, A. (2016): «Proyecto Silos: difusión y revalorización del patrimonio industrial abandonado», Revista $\mathrm{PH}, 89$ (abril): 19.

Bocanegra, A. y Rodríguez, B. (2016): «Proyecto Silos. Difusión y vías de conocimiento del patrimonio industrial a través de la cultura digital», en F.J. SÁNCHEZ (coord.), Nuevas estrategias en la gestión del patrimonio industrial, Fundación Patrimonio Industrial de Andalucía y Universidad de Huelva, Sevilla: 223-233.

CAÑizares, M.C; Benito, P. y PAscual, H. (2019): «Los límites del turismo industrial en áreas desfavorecidas. Experiencias singulares en España», Cuadernos Geográficos, 58 (1): 180-204. http://dx.doi.org/10.30827/cuadgeo.v58i1.6746.

CAstillo, J. (dir.) (2013): Carta de Baeza sobre patrimonio agrario, UNIA, Sevilla.

Diputación Provincial de Ciudad Real (2020): Proyecto Titanes (documento inédito).

DOREL-FerRé, G. (coord.) (2014): Les silos, un patrimoine à inventer, Université de Savoie, Chambéry.

Fernández, V.; Marcelo, V.; Valenciano, J.V. y López-Díez, F.J. (2017): «History, construction characteristics and possible reuse of Spain'snetwork of silos and granaries», Land Use Policy, 63: 298-311. https://doi.org/10.1016/j. landusepol.2017.01.017

FERNÁNDEZ OsunA, J.M. (2016): «Silo Fuentes de Andalucía, mirador de la campiña. Gestión de un patrimonio singular», en F.J. SÁNCHEZ (coord.): Nuevas estrategias en la gestión del patrimonio industrial, Fundación Patrimonio Industrial de Andalucía y Universidad de Huelva, Sevilla: 205-220.

GARCía GAYO, E. (2019): «El espacio intermedio del arte urbano», Ge-conservación, 16 (diciembre): 154-165.

Garrido, M., Santiago, J.M. y Lafuente, F.J. (2017): «Silos, Reused MachineBuildings: A Proposal for Its Transformation», IOP Conference Series: Materials Science and Engineering, 245: 1-10. http://dx.doi.org/10.1088/1757899X/245/8/082051. 
GonzÁlez, M.J. y Rodríguez, A. (2019): «La decadencia de los silos en Tierra de Campos en la región de Castilla y León (España)», Anales de Geografía de la Universidad Complutense, 39 (1): 59-83. http://dx.doi.org/10.5209/ AGUC.64677.

Herrera, A.R. (2011): «Un mapa conceptual para el arte urbano», Nodo: Arquitectura. Ciudad. Medio ambiente, 11 (6): 7-22.

ICOMOS. International Council on Monuments and Sites (2003): Carta de Nizhny Tagil sobre Patrimonio Industrial.

JoRDANO, M.A. (2012): «El silo de Córdoba, un ejemplo de arquitectura industrial», BSAA Arte, 78: 261-278.

LANDI, S. (2019): «Rural landscapes of the 20th century: from knowledge to preservation», Architecture Civil Engineering Environment, 12 (2): 47-56. http:/ / dx.doi.org/10.21307/ ACEE-2019-022.

Mendoza, J. (2011): Los silos de Extremadura. Reutilización del patrimonio industrial agrario, Universidad de Sevilla, Sevilla.

Revilla, J. (2015): La economía de posguerra en la provincia de León (1937-1953): El Servicio Nacional del Trigo, los molinos y las fábricas de harinas. Los años del hambre y el estraperlo, Tesis Doctoral, Universidad de León, León.

SALAmAnCA, D.S. (2008): Los gigantes del siglo Xx. Reinterpretación en el siglo XXI DEA, Universidad de Sevilla, Sevilla.

Salamanca, D.S., Ceballos, C.M. y Gordo, A.A. (2012): «Ingeniería 20-Arquitectura 21. Los silos de cereal», en II Jornadas andaluzas de patrimonio industrial y de la obra pública, Fundación Patrimonio Industrial de Andalucía, Sevilla: 1-8.

Salazar, A. (2015): Del trigo al hombre. Rehabilitar el silo, Tesis de Maestría, Universitat Politècnica de Catalunya, Barcelona.

SÁnCHEZ Mustieles, D. (2011): «El patrimonio arquitectónico, el gran olvidado del siglo XX», en CAH 20thC International Conference Intervention Approaches for the 20th Century Architectural Heritage, Centros de Intervención en el Patrimonio Arquitectónico del S20, Madrid: 1-7.

Sobrino, J. (1996): Arquitectura industrial en España, 1830-1990, Cátedra, Madrid.

Sobrino, J.; SANZ, M. (eds.) (2018): Carta de Sevilla de Patrimonio Industrial. Los retos del siglo XXI, Centro de Estudios Andaluces, Sevilla.

TsaKonas, A. (2019): «Victoria's Silo Art Trail», Fabrications, 29 (2): 273-276. http:/ / dx.doi.org/10.1080/10331867.2019.1566984.

Vidigal, C. (2019): Rascacielos rurales: el silo de Olivenza. Análisis y puesta en valor del patrimonio agrícola, Escuela Técnica Superior de Arquitectura, Sevilla. 
